\title{
Fish hook injuries of the eye
}

\author{
R. S. BARTHOLOMEW AND MARGARET MACDONALD \\ From the Department of Ophthalmology, University of Edinburgh
}

SUMmary Two cases of fish hook injuries to the eye are described. Both were removed successfully by rotating the hook through undamaged tissue before snipping off the barb. Good vision was restored without complications for periods of 12 and 18 months.

A barbed fish hook embedded in the eye is an injury unlikely to be forgotten by any ophthalmic surgeon. Reported incidents of this kind are rare, however. ${ }^{12}$ Two such cases are described in this paper. In both our patients the injury was caused by a 3-pronged steel salmon hook, one of the prongs with its barb penetrating the globe.

Fish hook injuries most commonly occur in the hand. The standard method used to remove them from this site is to push the barb out through the skin, snip it off, and then rotate the shaft backwards along the entry path. ${ }^{3}$ If the hook is simply dragged backwards with the barb in situ it produces much greater soft tissue damage.

We decided to remove the hooks in our patients by this method, as they were so large.

\section{Case reports}

CASE 1

A man aged 39 was casting for salmon. His line was deflected by small twigs, and the hook embedded itself in his right eye. He cut off the line but made no attempt to remove the hook.

On examination (Fig. 1) one of the prongs was seen to have penetrated the cornea, injuring the iris and lens. Under general anaesthesia the hook was rotated so that the intraocular barb emerged through the angle, counter pressure being applied each side of the exit wound. The barb was snipped off with wire cutters and the shaft then removed through the entry wound.

The traumatic cataract was aspirated 36 days later and a soft contact lens fitted. Eighteen months after injury the eye was free from complications and had regained 6/9 vision (Fig. 2).

Correspondence to Dr R. S. Bartholomew, Department of Ophthalmology, University of Edinburgh, Eye Pavilion, Chalmers Street, Edinburgh EH3 9HA.

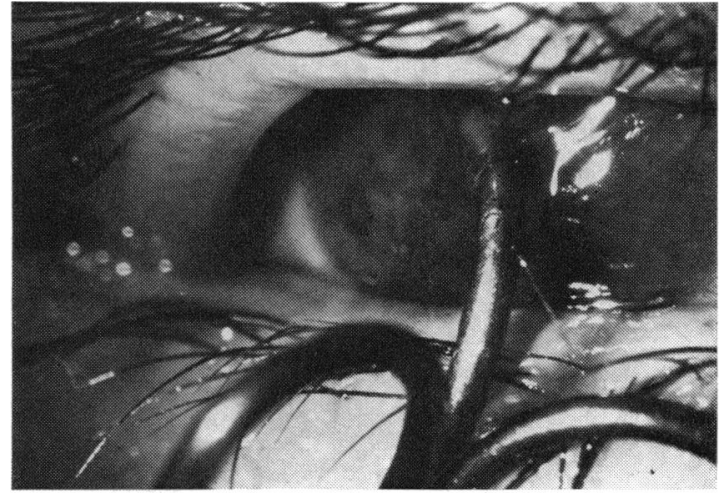

Fig. 1 Case 1: barb piercing central cornea

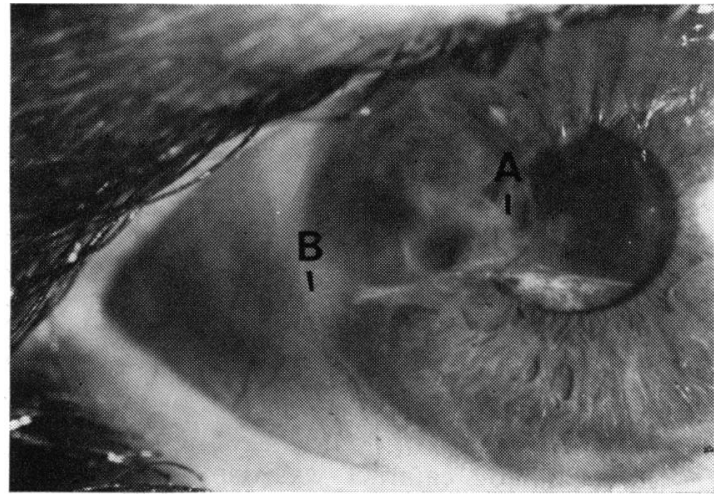

Fig. 2 Case 1: 12 months after injury, entry wound in central cornea $\mathrm{A}$, exit wound at limbus $\mathrm{B}$

CASE 2

A man aged 21 was rowing a boat for salmon fishermen when a hook cast by one of them caught in his left eye. No attempt was made to remove it but the line was cut off. 


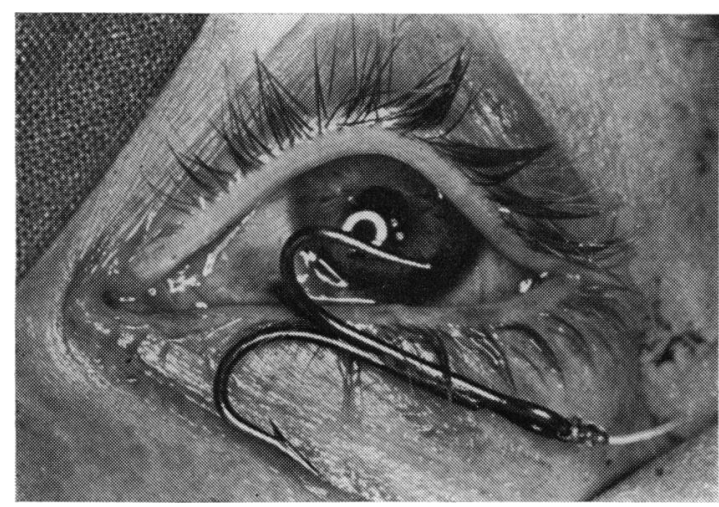

Fig. 3 Case 2: barb piercing nasal ciliary body

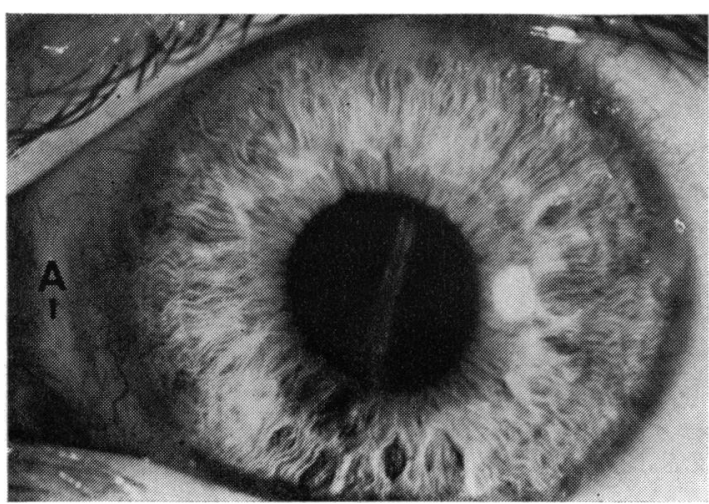

Fig. 5 Case 2: 3 months after injury, entry wound in sclera $\mathrm{A}$, exit wound in peripheral cornea at $6 o^{\prime}$ clock

On examination one of the prongs had penetrated the sclera over the nasal ciliary body, and the barb lay in the posterior part of the lens (Fig. 3). Under general anaesthesia the barb was rotated to emerge just behind the iris at 6 o'clock (Fig. 4). Prior to this manoeuvre the 2 extraocular barbs were amputated, as their position made the manipulation difficult. Tin snips were used to remove the 3 barbs, as steel wire cutters proved ineffective in this case. Removal of the shaft was then completed through the entry wound.

The traumatic cataract was aspirated 45 days later and a soft contact lens fitted. Twelve months after injury, there were no complications and the visual acuity was $6 / 9$ (Fig. 5).

\section{Discussion}

Large intraocular foreign bodies are associated with a poor prognosis. ${ }^{4}$ The hooks removed from our patients' eyes were large (Figs. 1, 3, 5, and 6), but

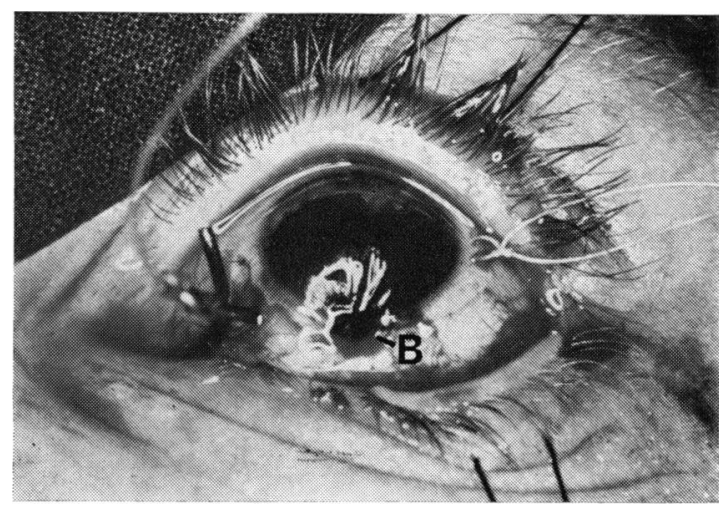

Fig. 4 Case 2: entry and exit (B) wounds before removal of hook

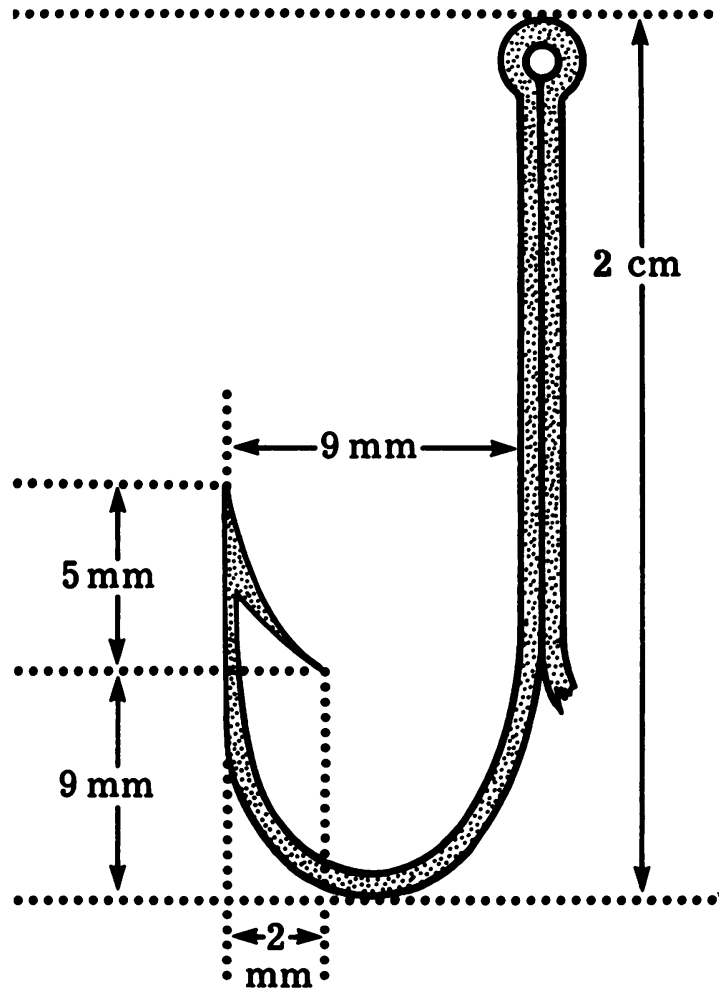

Fig. 6 Diagram of no. 4 salmon hook

the eventual visual results were good. The appearance of an eye with such a hook embedded in it is daunting to patient and surgeon alike, but removal by the method outlined in this paper is fairly simple and in our 2 cases has not led to any complications.

The manoeuvre of pushing the hook out through the eye is the same movement used in manipulating 
a curved suture needle and is one familiar to all surgeons. If technically possible it would seem best to push the hook out through the peripheral cornea as described in one of the cases reported by Lugli and Vallavanti, ${ }^{1}$ but in neither of our cases was this feasible, and no complications arose as a result of the exit wound being made in the region of the iris root. The shaft of the hook should be left long to facilitate manipulation. The extraocular barbs may have to be removed; powerful steel cutters are therefore essential.
We are grateful to Colin Hood, photographer, University of Edinburgh for the illustrations, and to Dr H. B. Chawla, consultant ophthalmologist for permission to report case 2 .

\section{References}

${ }^{1}$ Lugli L, Vallavanti C. Eyeball trauma due to fishing. Atti Soc Oftal Lomb 1967; 22: 365-70.

${ }^{2}$ Cullen JF, ed. Blindness from Accident (W. H. Ross Foundation). Edinburgh: Blackwood, 1976.

${ }^{3}$ Bailey H, Love M. A Short Practice of Surgery, 11th ed. London: Lewis, 1959: 13.

${ }^{4}$ Duke-Elder S. Mechanical Injuries. System of Ophthalmology. London: Kimpton, 1972: 14: Part 1, 30, 481. 